Edgeworth and Gerard Kuiper sketched out these ideas in somewhat more detail in the 1940s, and disagreement persists as to who should get the credit (and the eponymous immortality). To the dynamicist, the history of the Kuiper belt really begins in the 1980s, when models were developed to try to explain the origin and observed distribution of shortperiod comets (comets that take 200 years or less to orbit the Sun).

To the Solar System observer, depending on whether they are a heretic or a purist, the beginning of our foray into the Kuiper belt would be either the discovery of Pluto in 1930, the discovery of the centaur (outerplanet-crossing asteroid) Chiron in 1977, or the discovery of the first 'classical' Kuiperbelt object in 1992. The Kuiper belt is many things to many people: to the planetary scientist it holds clues to the origin of the Solar System, frozen into its distribution and dynamics during its formation. To the stellar astronomer it is a local example of extended structures we see around some other stars.

All this raises the question of how one can write a history of a topic that is a moving target, and that is, in many ways, still in the first blush of youth, maturing as one writes. Even since this book went to press there have been exciting new discoveries: trans-neptunian objects (TNOs) that are comparable in size to Pluto's moon and the asteroid Ceres; the first binary TNO; TNOs bright enough to be found on pre-discovery plates dating back many decades; and objects on unexpected orbits that have yet to be explained.

John Davies solves this predicament very well by setting out to tell a story and to show the reader that this is an ongoing adventure. The book's dust-jacket describes it as "the fascinating story of how theoretical physicists decided that there must be a population of unknown bodies beyond Neptune and how a small band of astronomers set out to find them". Davies points out that the book is not intended as a textbook, although he hopes (and succeeds, it seems to me) that it gives a feeling for how astronomy is actually done. With that intention, the reader is brought into the story almost as a participant, getting to know some of the personalities involved.

Although the popular idea is that individual personality does not have a role in the impersonal pursuit of science, this story nicely illustrates that it is exactly those unique traits that drive someone to search doggedly over many years for objects they don't even know exist, or to write and wrestle with numerical simulations that must run for months at a time to step through possible billion-year histories of model solar systems. In this book, Davies blends personal histories with scientific theory to give us an astronomical primer on the outer Solar System. $\mathrm{He}$ includes a fair amount of self-aware humour about the public and research community's image of astronomy: "Some physi-

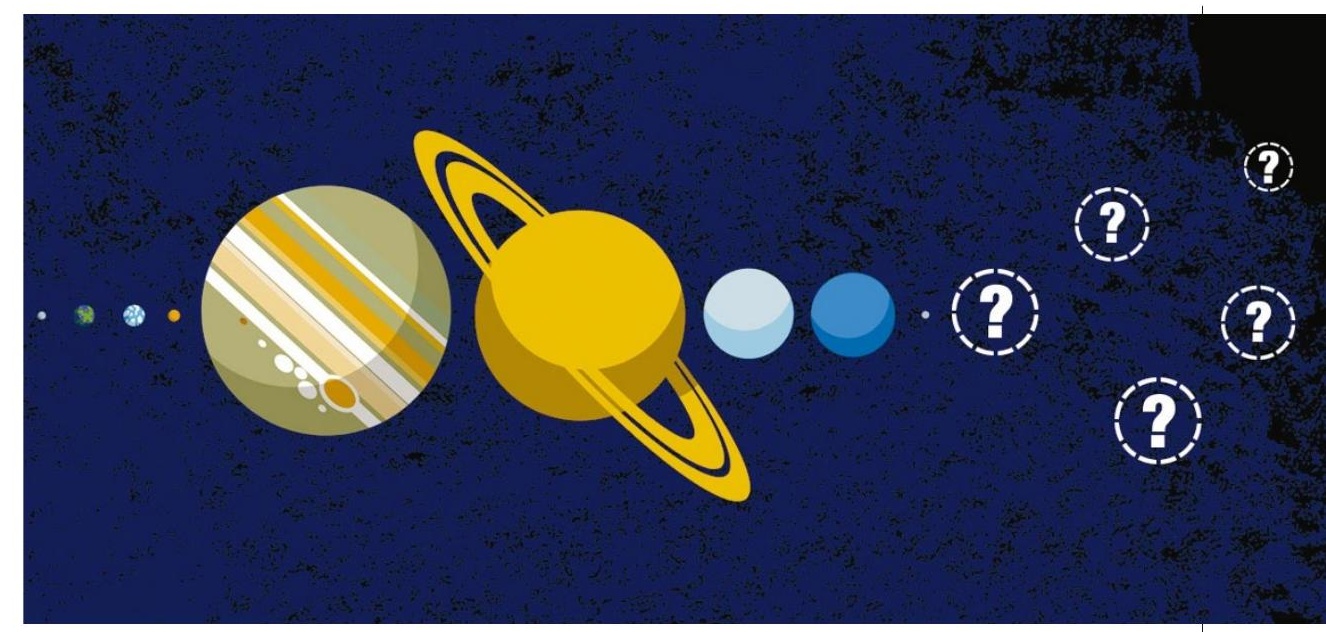

cists joke that the fundamental equation of astronomy is that 1 is approximately equal to 10." This personal touch extends to an appendix listing the main belt asteroids that have been named after Kuiper-belt researchers, along with the associated citations describing their work.

Because of the informal conversational style, the story sometimes hops around a bit and reiterates certain themes. Early on, for example, Davies discusses how Edgeworth was the first to put forward the possibility of a disk in the outer region of the Solar System containing small bodies orbiting the Sun. But in the final chapter, more suspects are named (Fred Whipple, Armin Leuschner and Frederick Leonard) who, it could be argued, have the earlier or stronger claim to postulating the existence of small bodies in the trans-neptunian region. If Leonard had got the glory and his term "ultra-neptunian objects" had stuck, then we might now be talking about "UNOs in the Leonard belt".

The introduction of a new concept in the text often leads to tangents that one may find informative, amusing or distracting according to taste (star formation, photometry, the effects of oxygen-deprived observing on Mauna Kea). When discussing the introduction of charge-coupled devices (CCDs) into astronomy as the detector of choice (nearly universally replacing the old standby photographic plate), Davies takes a small sidetrack to explain how they work, which includes an analogy of how a farmer would measure rainfall in his field using labourers with buckets. I found these tangents usually enjoyable, enhancing the informal 'telling a story' style and readability of the book.

Just as the Kuiper belt means different things to different people, there is something here for everyone. For the non-professional, Davies discusses the tools and art of astronomical research in a practical manner. For this level of general consumption, a glossary would have been useful, and the more abstract parts of dynamics, orbital interactions and resonance sweeping, as well as the various orbit diagrams and orbital element plots may be somewhat difficult for nonexperts to disentangle and appreciate. For the expert and research astronomer, this account provides context for the ongoing work in the field as well as an excellent overview of the driving questions and current state of knowledge. For this level, a bibliography would have been beneficial.

But it is a pleasure to have a book that is readable at so many levels and able to describe the concepts and relevance of such a new field of research. With the discovery of the Kuiper belt, our view of our Solar System has expanded in many dimensions at an amazing pace. In the nine years since the discovery of the first TNO (not counting Pluto) to the publication of this book, we have discovered as many objects in the Kuiper belt as it took 100 years to discover in the main asteroid belt. Let's hope that this momentum will continue, with more public recognition of the new worlds to be explored and understood.

Joel Wm. Parker is at the Southwest Research

Institute, 1050 Walnut Street, Boulder,

Colorado 80302, USA.

\section{The other man to discover evolution}

Alfred Russel Wallace: A Life by Peter Raby

Chatto \& Windus/Princeton University Press: 2001. 352 pp. $£ 20, \$ 26.95$

\section{Jane R. Camerini}

One can only welcome a new biography of one of Britain's most interesting and least celebrated nineteenth-century naturalists, Alfred Russel Wallace. Known during the twentieth century primarily as the man who spurred Charles Darwin to publish his work on the origin of species, and to biologists as one of the founders of modern biogeography, Wallace has, by and large, been relegated to the periphery of the present-day picture of 
Victorian science and culture.

Yet he was the co-discoverer of one of the most significant scientific theories of all time, and a passionate and articulate public intellectual who held forth on an enormous range of political, social and theological, as well as scientific, issues. An advocate of evolution by natural selection, certainly, and of socialism, spiritualism, anti-vaccination and women's rights, Wallace had an unusual following, more chequered and less strictly scientific than that of his more famous peers, such as Thomas Huxley and Darwin.

The anti-establishment leanings of his varied commitments, along with his unease in the social milieu of élite scientific society, contributed to the fact that Wallace never held a regular paid position, and to the fact that he is neglected and even disdained by some historians and scientists. Although celebrated writers such as A. S. Byatt and Andrea Barrett have found inspiration for their fiction in Wallace's intriguing life, he has not until now received his due from historians. Peter Raby's energetic account of Victorian scientific travellers, Bright Paradise (Princeton University Press, 1996), put Wallace's journeys to tropical Brazil and Indonesia in their historical and cultural context. His new book provides a focused and balanced narrative of Wallace's life, in which his exotic travels are placed in the context of his eventful life story.

Born in 1823 in Wales, Wallace made his way from land-surveying in early industrial Britain to working as a naturalist in the wilds of the Amazon basin by the age of 25. A selftaught natural scientist, paying his way by collecting insects and birds to sell to the then-thriving trade in specimens of natural history, Wallace's immodest goal was to find a theory to explain the origin of species.

Raby skilfully draws readers into Wallace's story, which ranges from an unremarkable upbringing to the rapids of the Rio Negro, from tropical shipwreck to strolling in London's Regent's Park. We follow Wallace as he braves London's scientific social world, and departs once again, this time to the islands of the Malaysian archipelago in search of new evidence for his growing "obsession", as Raby calls it, with understanding the laws that govern the variation and distribution of species.

Raby relates with a biographer's remove Wallace's discovery of the dynamic law subsequently called natural selection - that underlies the formation of new species. And he tackles Wallace's return to England and his subsequent infatuation with spiritualism using a combination of insight and authorial scepticism. Of note is Raby's perception that, when investigating seances and other spiritualist phenomena, "Wallace's conviction threshold was lowered whenever he came across some apparent fact or reference involving a member of his family... For Fanny
[Wallace's sister] and Alfred, the certainty that they were in touch with their dead brothers and sisters formed the bedrock of their spiritualist convictions." Given that six of Wallace's eight siblings were dead, this adds a personal dimension to Wallace's belief. Subsequent developments of Wallace's scientific and social commitments, and his journey to North America, are also covered.

Raby expands our understanding by his thorough research of manuscript material, particularly letters and other documents in the Wallace family archives, as well as a conscientious use of published and archived letters of his contemporaries. His familiarity with Victorian literature and drama adds sensitivity to his portrait of Wallace, who read widely throughout his life in spite of his lack of higher formal education.

Well researched and ably written — and a definite improvement on the few existing biographies of Wallace - the book is nonetheless mildly disappointing, particularly for historians of science. Raby's thick-brush treatment of the science of Wallace's day is superficially lively, providing an overview from the outside, but only begins to relate the enormous upheaval surrounding the new findings and new interpretations of the history of humankind that so dominated the public intellectual scene in the 1860s. Here, as elsewhere, Raby seems to skim over recent work in the history of science.

In recent decades, the bar has been raised for scientific biography with Adrian Desmond and James Moore's Darwin, Janet Browne's Charles Darwin and Adrian Desmond's Huxley, in which biographical narratives are embedded in finely textured political and social contexts. Raby's strategy of sticking fairly closely to the rich set of sources he has gathered proves to be a double-edged sword. He provides readers with a well-documented biography that covers the principal events of Wallace's life, but a deeper and broader historical sensibility — in which connections are made among the activities of scientists, the content of scientific work, and the broader social, cultural, political and scientific contexts - is wanting.

I would recommend this tastefully illustrated book to general readers as a good introduction to one of Britain's more charismatic and difficult figures of the nineteenth and early twentieth centuries. Historians of science will probably find some new information and will continue to wonder about the unresolved questions of Wallace's role in the history of science.

Jane R. Camerini is in the Department of the History of Science, University of Wisconsin, Madison, Wisconsin 53706, USA. Her forthcoming book The Alfred Russel Wallace Reader: A Selection of Writings From the Field (Johns Hopkins University Press) will be published later this year.

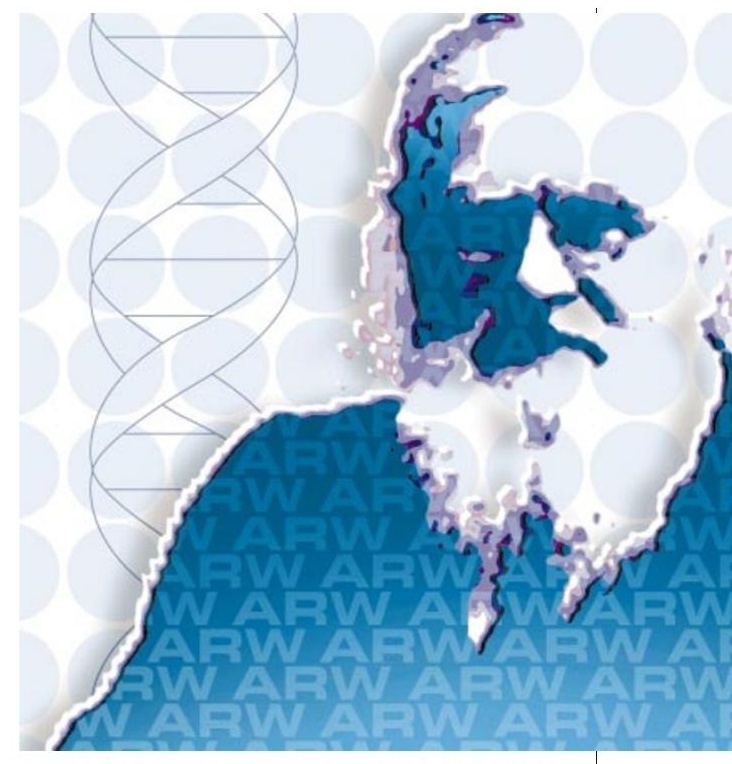

Unlocking nature's ancient secrets

\section{The Molecule Hunt: Archaeology and the Search for Ancient DNA by Martin Jones}

Allen Lane: 2001. 280 pp. 118.99

\section{Tomas Lindahl}

Traditional archaeological research describing skulls and pottery fragments has expanded in recent years to the use of genetic and biochemical methods in pursuit of the origins of humans, domestic animals and agriculture. The rewards have been great, and structural determinations of DNA and other macromolecules in ancient materials have transformed the field almost as much as DNA analysis has enhanced forensic medicine. For example, an unknown genius in southeastern Turkey, about 10,000 years ago, must have dramatically altered human life patterns by domesticating wild cereals, thereby initiating agriculture. The later exploitation of wild maize in America may have been a more gradual process.

DNA sequencing has enabled us to trace the origins of horses, dogs and cattle as human domestic animals in a detail that was hard to imagine a few years ago. The huge and fierce aurochs, depicted in cave paintings and at ancient grave sites, now emerges as a kind of bovine Neanderthal, extinct and not a direct precursor of modern cattle.

Martin Jones tells the intriguing story of the new field of bioarchaeology in this timely book. From his position as the George PittRivers Professor of Archaeological Science at Cambridge University, and chairman of the UK Ancient Biomolecules Initiative, he has had a broad and unique overview of the rapid evolution of this new area of research, 